\title{
Influence of age, systemic blood pressure, smoking, and blood viscosity on orbital blood velocities
}

\author{
Tom H Williamson, Gordon D O Lowe, Grant M Baxter
}

Tennent Institute of Ophthalmology, Glasgow TH Williamson

\section{Department of Radiology, Western Infirmary, Glasgow} G M Baxter

University Department of Medicine, Royal Infirmary, Glasgow G D O Lowe

Correspondence to: Tom H Williamson, Tennen Institute of Ophthalmology, Western Infirmary, Glasgow G11 6NT.

Accepted for publication 19 August 1994

\begin{abstract}
The influence of multiple systemic factors upon the blood velocities obtained from the orbital circulations was investigated. The velocities obtained by colour Doppler imaging from the ophthalmic artery, central retinal artery, and vein from 95 ophthalmologically healthy volunteers were analysed. The effects of age, systemic blood pressure, and smoking habit were examined. In 24 volunteers blood viscosity was also measured and its relation with blood velocity assessed. Age was weakly negatively correlated with the blood velocities in the ophthalmic artery and weakly positively correlated with resistance to flow in the retinal circulation. Systolic blood pressure showed a positive correlation with the peak systolic velocities in the arteries while cigarette smoking was associated with lower ophthalmic artery velocities. Increased haematocrit and viscosity were positively correlated with resistance to flow proximal to the ophthalmic artery and red cell rigidity negatively correlated with the pulsatility of flow in the retinal vein. These results help to identify the roles of systemic conditions in the ocular circulation. The influence of blood viscosity on retinal venous flow may be relevant to the pathogenetic mechanisms of conditions such as central retinal vein occlusion.
\end{abstract}

(Br f Ophthalmol 1995; 79: 17-22)

Colour Doppler imaging allows examination of the pulsatile velocity of blood in the orbital vessels $\mathrm{s}^{1-3}$ and has been used in the investigation of a number of vascular ophthalmic disorders. ${ }^{49}$ Although the effects of posture ${ }^{3}$ and intraocular pressure $^{510}$ have been investigated, the effects of various systemic factors upon the blood velocities obtained by this technique are as yet unknown. In this study the influence of age, systemic blood pressure, smoking habit, and arteriopathy were examined in a control population to determine their effect on these haemodynamic variables.
In addition, blood rheology, which may have a profound effect on the blood flow of the eye and has been implicated in number of ophthalmic vascular disorders ${ }^{11-15}$ was examined in a group of volunteers also examined by colour Doppler imaging. The relation between the rheology of the blood and its pulsatile velocities was therefore investigated and interpreted with reference to the pathogenesis of ocular diseases.

\section{Subjects and method}

\section{SUBJECTS}

Ninety five volunteers were examined to provide control data and consisted of staff of the ophthalmology or radiology department at the Western Infirmary Hospital, Glasgow and relatives of patients attending the ophthalmology outpatient department. The volunteers were asked for history of general medical and ocular conditions, drug usage. Smoking habit was recorded as one of the following: (1) Non-smoker, (2) ex-smoker, (3) smokes less than 20 cigarettes each day, (4) smokes at least 20 cigarettes each day, (5) pipe or cigar smoker.

Subjects with a history of previous ophthalmic disorders were excluded. Systemic blood pressure was measured using a digital sphygmomanometer (AND Company, Japan). One orbit only of each volunteer was examined (right or left eyes were chosen by random number sequences). Hospital ethics committee approval was obtained and informed consent was obtained from all of the volunteers before examination.

\section{COLOUR DOPPLER IMAGING}

The examination protocol has been fully described previously. ${ }^{3}$ In short, the patients were examined by colour Doppler imaging using an Acuson 128 (Mountain View, CA, USA) with a $7.5 \mathrm{MHz}$ probe with the subject in the supine position. After identification of the vessel of interest in the orbit by the use of coloured pixels on a video display unit (which denote Doppler
Figure 1 A spectral analysis of the blood velocities detected in the central retinal artery (above the line) and the central retinal vein (below the line) showing the pulsatile velocities in the vein which are in synchrony with the pulsations in the artery.

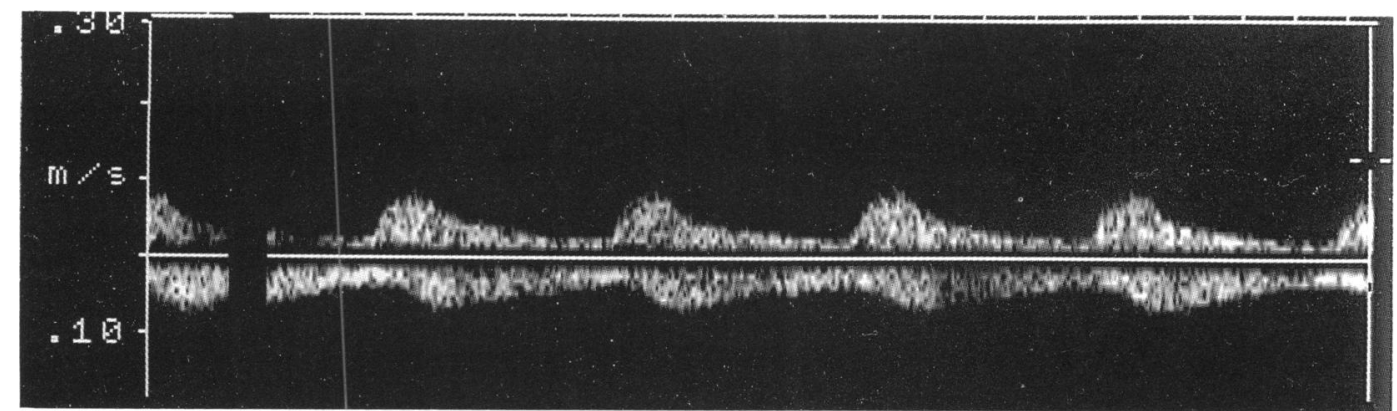


frequency shifts), pulsed Doppler is used to obtain a spectral waveform of the velocity of the blood. Peak systolic velocity (PSV) and peak end diastolic velocity (EDV) in the ophthalmic and central retinal arteries and maximum peak velocity $(V \max )$ and minimum peak velocity (Vmin) in the central retinal vein were recorded.

Resistive index was calculated for the arteries from the formula:

$$
\text { Resistive index }=\frac{\text { PSV }- \text { EDV }}{\text { PSV }}
$$

This measure was described by Pourcelot as a measure of the peripheral resistance to flow in arteries. ${ }^{16}$ In the case of the central retinal vein the following formula was used:

$$
\text { Venous pulsatility index }=\frac{V \max -V \min }{V \max }
$$

This measure was employed because the central retinal vein possesses an unusual pulsatile pattern of flow which is not normally seen in other veins in the body. The velocities in this vessel vary in synchrony with the cardiac cycle (Fig 1) whereas other veins show variations with the change in intrathoracic pressure from the respiratory cycle. Examination of an individual with an anomalous retinal vein has revealed that this pulsatile pattern arises because of the close approximation of the central retinal artery and vein in the optic nerve. ${ }^{17}$

\section{CORRELATIONS WITH SYSTEMIC FACTORS}

The influence of age, right or left eye, sex, systolic and diastolic blood pressure, cigarette smoking, and the presence of systemic vascular disease were examined by multiple linear regression analysis or analysis of covariance where appropriate. $R$ and $\mathrm{p}$ values for analysis of covariance (ANCOVA) and b values for multiple linear regression analysis are provided (results were described as significant at $\mathrm{p}<0.05$ ).

\section{BLOOD VISCOSITY}

Twenty four of the volunteers had blood rheology examined on the same day as their colour Doppler imaging. Venous blood was sampled from an antecubital vein with a 21 gauge butterfly needle after minimal use of a tourniquet. Blood was anticoagulated with dipotassium edetate $(1.5 \mathrm{mg} / \mathrm{ml})$ for viscosity examination which was performed within 4 hours of sampling. Whole blood viscosity and plasma viscosity were measured at high shear rates (more than 300/s) in a capillary viscometer (Coulter-Harkness) at $37^{\circ} \mathrm{C}$, haematocrit (Hawksley microhaematocrit, $13000 \mathrm{~g}$ for 5 minutes), and red cell aggregation (photometric aggregometer, Myrenne $\mathrm{GmbH}$, Roetgen, Germany).

There are many ways in which blood viscosity can be increased. Haematocrit has the greatest influence upon the whole blood viscosity in larger vessels. To allow an estimation of the contribution of other factors - for example, plasma viscosity, red cell aggregation and red cell deformability, haematocrit corrected blood viscosity was calculated ${ }^{18}$ :

\section{$\mathrm{CBV}=\mathrm{PV} \times \operatorname{Exp}(\log \mathrm{WBV} / \mathrm{PV} \times 45 / \mathrm{Hct})$}

where $\mathrm{CBV}=$ corrected blood viscosity, $\mathrm{PV}=$ plasma viscosity, $\mathrm{WBV}=$ whole blood viscosity, $\mathrm{Hct}=$ haematocrit.

Furthermore, by calculating relative blood viscosity from the ratio of haematocrit corrected blood viscosity to plasma viscosity the relative contribution of the cellular abnormalities (increased red cell aggregation and reduced red cell deformability) to the whole blood viscosity can be estimated:

\section{Relative blood viscosity $=\mathrm{CBV} / \mathrm{PV}$}

\section{Results}

The mean age of the volunteers was $47 \cdot 1$ (SD 17.6) years; 50 were male and 45 female. Their mean systolic and diastolic blood pressures were $127 \cdot 7(18 \cdot 0) \mathrm{mm} \mathrm{Hg}$ and $77 \cdot 2(9 \cdot 5) \mathrm{mm} \mathrm{Hg}$, respectively. The Doppler results from the control population have been presented fully elsewhere and are summarised in Table 1.

\section{AGE}

The ophthalmic artery blood velocities were negatively correlated with age (both peak systolic and end diastolic velocity provided $r=-0.31$, $\mathrm{p}=0.003$, Fig 2) and resistive index in the central retinal artery and venous pulsatility index in the vein were positively correlated with age $(r=0 \cdot 21$, $\mathrm{p}=0.04$, and $r=0.54, \mathrm{p}<0.00001$, Fig 3 ). The blood velocities in the central retinal artery and vein demonstrated no correlations with the age of the individual. The resistive index recorded in the central retinal artery and the venous pulsatility index in the vein were positively

Table 1 The means (SD), confidence limits, and range of values are shown for the ophthalmically healthy volunteers for

\begin{tabular}{|c|c|c|c|c|c|}
\hline & \multirow[b]{2}{*}{ Range } & \multirow[b]{2}{*}{ Mean } & \multirow[b]{2}{*}{$S D$} & \multicolumn{2}{|c|}{ Confidence limits } \\
\hline & & & & Upper & Lower \\
\hline \multicolumn{6}{|c|}{ Ophthalmic artery } \\
\hline PSV & $11 \cdot 0-65 \cdot 0$ & $35 \cdot 0$ & $11 \cdot 2$ & $37 \cdot 3$ & $33 \cdot 5$ \\
\hline PEDV & $1.9-23.0$ & $8 \cdot 6$ & $3 \cdot 8$ & $9 \cdot 4$ & $7 \cdot 8$ \\
\hline RI & $55 \cdot 7-89 \cdot 7$ & $74 \cdot 0$ & $8 \cdot 2$ & $75 \cdot 8$ & $72 \cdot 4$ \\
\hline \multicolumn{6}{|c|}{ Central retinal artery } \\
\hline PSV & $4 \cdot 6-18 \cdot 6$ & $10 \cdot 2$ & $2 \cdot 8$ & $10 \cdot 8$ & $9 \cdot 6$ \\
\hline PEDV & $1 \cdot 3-6 \cdot 3$ & $3 \cdot 1$ & $1 \cdot 1$ & $3 \cdot 3$ & $2 \cdot 8$ \\
\hline RI & $56 \cdot 0-89 \cdot 0$ & $69 \cdot 3$ & $7 \cdot 7$ & $70 \cdot 9$ & $67 \cdot 7$ \\
\hline \multicolumn{6}{|c|}{ Central retinal vein } \\
\hline Vmax & $3 \cdot 0-11 \cdot 0$ & $5 \cdot 7$ & $1 \cdot 4$ & $6 \cdot 1$ & $5 \cdot 4$ \\
\hline Vmin & $2 \cdot 0-7 \cdot 7$ & $3 \cdot 8$ & $0 \cdot 8$ & $4 \cdot 0$ & 3.6 \\
\hline RI & $13 \cdot 5-60 \cdot 0$ & $32 \cdot 4$ & $\mathbf{9 \cdot 7}$ & $34 \cdot 6$ & $30 \cdot 1$ \\
\hline
\end{tabular}
the ophthalmic artery and central retinal artery and vein

PSV = peak systolic velocity; $P E D V=$ peak end diastolic velocity; $\mathrm{RI}=$ restrictive index; $\mathrm{Vmax}=$ maximum peak velocity; $\mathrm{Vmin}=$ minimum peak velocity

Table 2 A comparison of the systemic parameters $(S D)$ in the patients who smoked and those who had never smoked. There were no significant differences found

\begin{tabular}{lcc}
\hline & Smoker & Non-smoker \\
\hline Age (years) & $49 \cdot 0(17 \cdot 9)$ & $49 \cdot 1(16 \cdot 9)$ \\
Systolic blood pressure (mm Hg) & $125(14 \cdot 4)$ & $128(19 \cdot 9)$ \\
Diastolic blood pressure (mm Hg) & $76(6 \cdot 1)$ & $80(13 \cdot 1)$ \\
Whole blood viscosity (mPas) & $3 \cdot 4(0 \cdot 7)$ & $3 \cdot 6(0 \cdot 7)$ \\
Plasma viscosity (mPas) & $1 \cdot 3(0 \cdot 07)$ & $1 \cdot 3(0 \cdot 09)$ \\
Haematocrit (\%) & $43 \cdot 8(4 \cdot 7)$ & $44 \cdot 6(2 \cdot 3)$ \\
Red cell aggregation (arbitrary units) & $4 \cdot 5(1 \cdot 3)$ & $4 \cdot 8(0 \cdot 5)$ \\
Corrected blood viscosity (mPas) & $3 \cdot 4(0 \cdot 4)$ & $3 \cdot 6(0 \cdot 5)$ \\
Relative blood viscosity & $2 \cdot 6(0 \cdot 2)$ & $2 \cdot 8(0 \cdot 3)$ \\
\hline
\end{tabular}


Table 3 The results of the examination of the various viscosity parameters in the comparison with the blood velocities in the orbital vessels

\begin{tabular}{lcc}
\hline & Mean & $S D$ \\
\hline Whole blood viscosity (mPas) & $3 \cdot 4$ & $0 \cdot 7$ \\
Plasma viscosity (mPas) & $1 \cdot 3$ & $0 \cdot 1$ \\
Haematocrit (\%) & $43 \cdot 3$ & $4 \cdot 3$ \\
Red cell aggregation & $4 \cdot 8$ & $0 \cdot 9$ \\
Corrected blood viscosity (mPas) & $3 \cdot 4$ & $0 \cdot 5$ \\
Relative blood viscosity & $2 \cdot 6$ & $0 \cdot 3$ \\
\hline
\end{tabular}

correlated to each other $(r=0.34$ and $\mathrm{p}=0.008$ by Spearman rank correlation).

Multiple regression analysis (including age and systemic blood pressure) confirmed the reduction in the velocities in the ophthalmic artery (both PSV and EDV were significantly correlated, $b=-0.62$ ) and the increase in resistive index in the central retinal artery (significant with $b=0.31$ ) and venous pulsatility index in the vein (significant with $b=0.40$ ) with age.

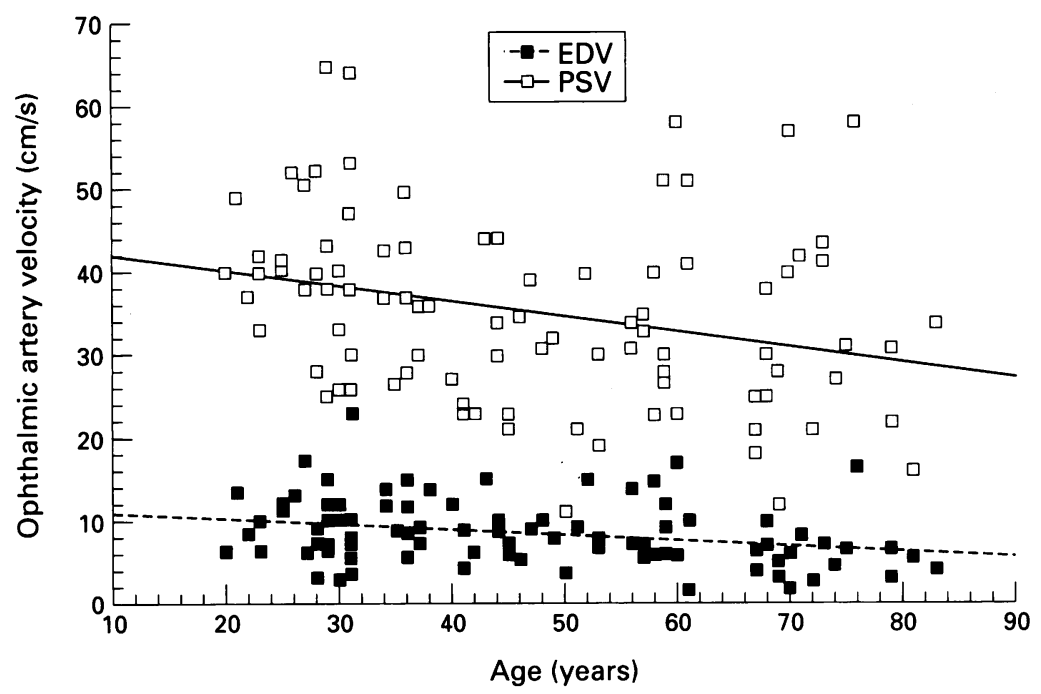

Figure 2 The blood velocities in the ophthalmic artery (peak systolic blood velocity (PSV) and end diastolic blood velocity $(E D V)$ ) are shown with a negative correlation (linear regression lines are shown).

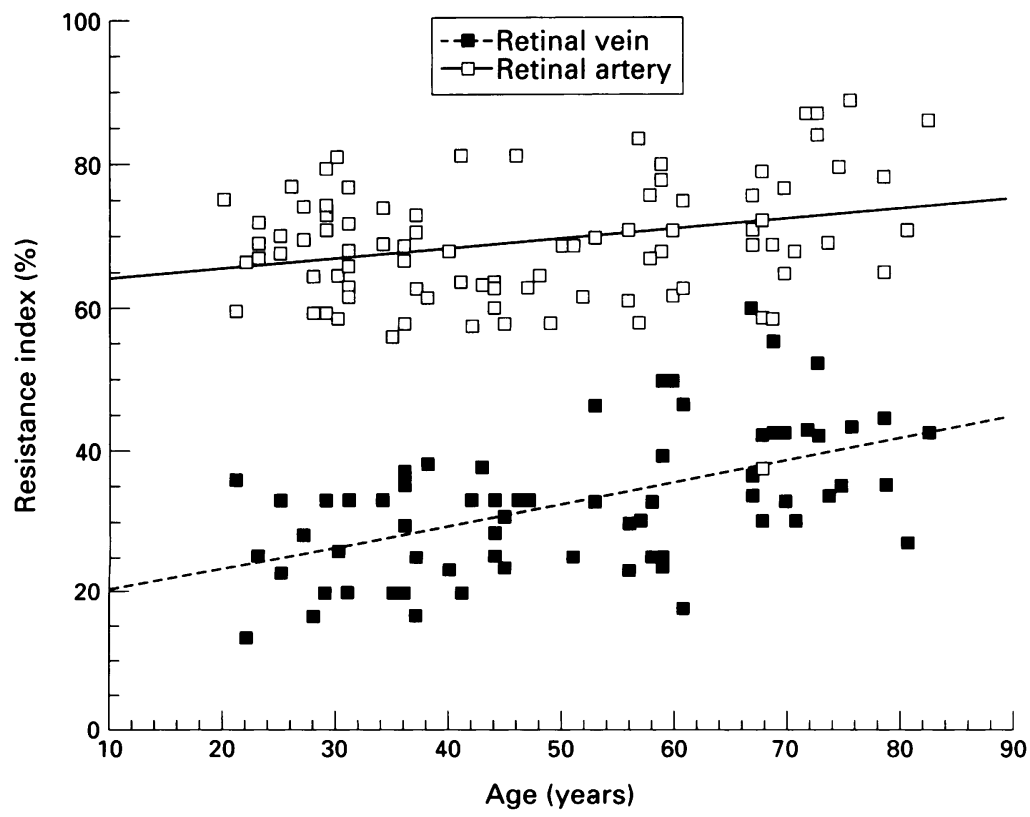

Figure 3 The resistive indices in the central retinal artery and vein are shown with a positive correlation (linear regression lines are shown).
SEX

There were no differences found for the velocity results for males or females by multiple linear regression (including age and systemic blood pressure).

\section{RIGHT OR LEFT EYES}

No significant differences were found in the Doppler results from right or left eyes.

\section{SYSTEMIC BLOOD PRESSURE}

The systolic and diastolic blood pressure increased with age (both $r=0.49$ and $\mathrm{p}<0.0001$ ). Multiple linear regression analysis (including age and systemic blood pressure) showed that the peak systolic velocity in both the ophthalmic and central retinal arteries significantly positively correlated with systolic blood pressure (ophthalmic artery $b=0.56$ and central retinal artery $b=0 \cdot 39$, Fig 4). Diastolic blood pressure showed no relation with the blood velocities.

\section{CIGARETTE SMOKING}

The data from 90 volunteers were available from which two pipe or cigar smokers were excluded leaving 19 smokers, 60 non-smokers, and nine ex-smokers for comparison by ANCOVA with the covariant age and systemic blood pressure. Mean ophthalmic artery peak systolic velocity was lower in smokers $(29.5(10.4) \mathrm{cm} / \mathrm{s})$ than non-smokers $(36.5(11 \cdot 2) \mathrm{cm} / \mathrm{s}, \mathrm{p}=0.03$, Fig 5$)$. The resistive index in the ophthalmic artery was lower in the smokers $(69 \cdot 7 \%(6.0 \%))$ than in nonsmokers $(75 \cdot 6 \%(8 \cdot 4 \%), p=0 \cdot 003)$. A comparison of the systemic parameters in the smokers and non-smokers showed no significant differences although there was a trend for increased viscosity variables (Table 2 ).

Ex-smokers had similar results to the nonsmokers: for example, in the ophthalmic artery a mean peak systolic velocity of $36.9(13.0) \mathrm{cm} / \mathrm{s}$ and a mean resistive index of $72 \cdot 1 \%(7 \cdot 1 \%)$ was found. The other Doppler measurements demonstrated no differences after statistical analysis.

\section{ARTERIOPATHY AND HYPERTENSION}

There was no difference in the Doppler measurements from healthy individuals and in a small group of five elderly patients with a history of arteriopathic disease (myocardial infarction, angina, or cerebrovascular accident) or with a group of eight patients on observation or treatment for systemic hypertension.

BLOOD VISCOSITY

Table 3 shows the mean viscosity values for the volunteers. Using multivariate linear regression analysis (including the age of the patient and when analysing the ophthalmic artery velocities systemic blood pressure) whole blood viscosity and haematocrit were significantly negatively correlated with the resistive index in the ophthalmic artery (both $b=-0.55$, Fig $6 A$ and $B$ ). Haematocrit corrected and relative blood 
viscosity were significantly negatively correlated with the pulsatility index in the vein $(b=-0.43$ and $b=-0.34$ respectively, Fig $7 A$ and $B$ ).

\section{Discussion}

The interpretation of the results of any blood flow analysis of the eye in the human must be performed with care because of the complex interaction of various parameters in haemodynamics. The primary objective of this study was to determine important factors which might affect the results of studies utilising colour Doppler imaging. In addition, discussion has been provided to explain where possible the results of the study, in particular with reference to the effects of age, systemic blood pressure, cigarette smoking, and blood viscosity, all of which have influenced the blood velocities obtained.

Age was found to be an important variable which affected the blood velocities - for example, the velocities in the ophthalmic artery significantly negatively correlated with age. A reduction in the peripheral perfusion in the elderly is the likely reason for this result. The correlation, however, was a weak one and accounts for only small part of the variations in the results between the individuals - for example, approximately $10 \%$ of the variation in the ophthalmic artery velocities. In contrast the blood velocities in the retinal circulation did not vary with age. The resistive index in the central retinal artery positively correlated with age (the resistive index in the ophthalmic artery was unaffected). The resistive index was designed as an estimate of the peripheral resistance to flow in arteries, therefore, the increase in resistive index in this vessel suggests an increase in the resistance in the

Figure 4 The effect of raised systemic blood pressure on the peak systolic blood velocities (PSV) in the ophthalmic ( $\square$ ) and central retinal ( $\mathbf{\square})$ artery are indicated demonstrating positive correlations with blood pressure (linear regression lines are shown).

Figure 5 The values for mean peak systolic velocity $(2 S E$ and $2 S D$ ) in the ophthalmic artery of smokers and non-smokers are illustrated. A reduction in the peak systolic velocity can be seen in those volunteers who smoke.
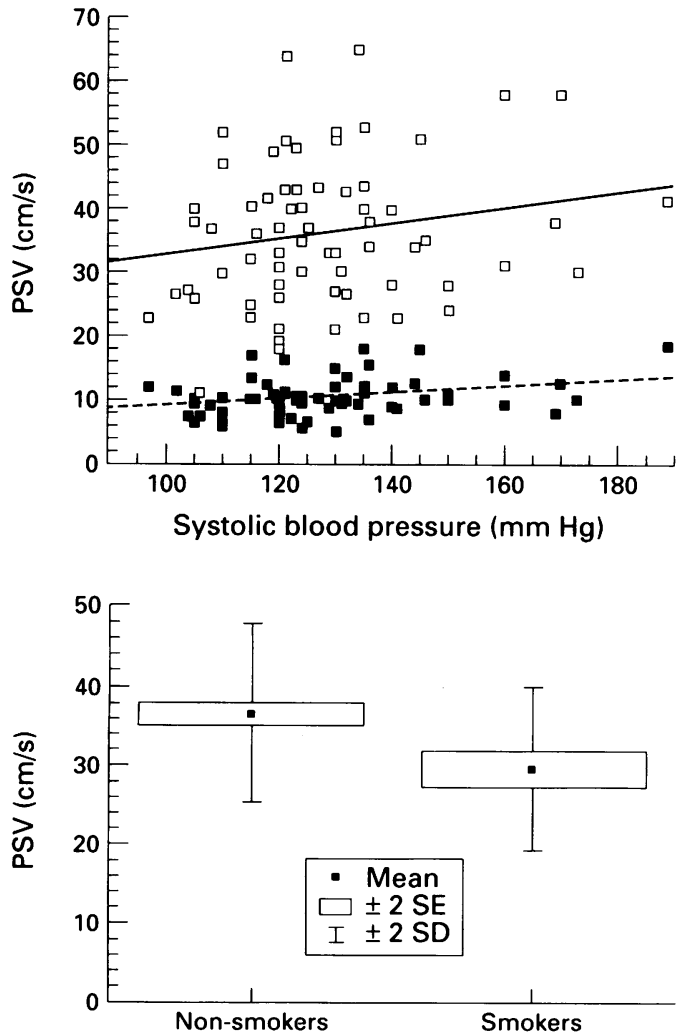

retinal circulation. ${ }^{16} \mathrm{~A}$ study employing the blue field simulation technique has found a reduction in the density of the capillary network and reduced blood velocities in the macula with age which may be associated with this increased resistance. ${ }^{19}$ That the blood velocities appear unaffected may reflect the need for the retinal circulation to attempt to maintain its blood flow despite increased resistance. Alternatively, the reduced reproducibility of the velocities in these small vessels may have masked the small effect of age on the results. ${ }^{20}$ In addition, the effects of stiffening or narrowing of the wall of the central retinal artery on these measures are unknown.

Although systemic blood pressure in these subjects increased with age and the velocities in the ophthalmic artery decreased with advancing age, systolic blood pressure was found to positively correlate with the peak systolic velocity in the ophthalmic artery and the central retinal artery. It is likely that this resulted from an increase in the perfusion pressure of the eye during systole in those patients with raised systolic blood pressure, thereby causing an increase in velocity of the blood during this phase of the cardiac cycle.

Cigarette smoking had the effect of reducing the peak systolic velocity and decreasing the resistive index in the ophthalmic artery only in those subjects who were still smoking and not those who had smoked in the past (ex-smokers). The finding may, therefore, be caused by the smoking of the cigarette itself rather than from the arteriopathy produced by the habit. The absorption of nicotine should produce constriction of the peripheral vasculature thereby increasing the peripheral resistance to flow and hence the resistive index. On the other hand, carbon monoxide is a cerebral vasodilator. Interpretation of this result is therefore difficult owing to the combination of the arteriopathy in smokers with the contrasting effects of the absorption of nicotine and carbon monoxide. In colour Doppler imaging studies in the future, subjects should be asked to refrain from smoking before the examination, in a similar fashion to patients being asked to avoid coffee drinking before blood flow analysis by other techniques. ${ }^{21}$ Only a small group of the subjects examined had known arteriopathy and in these no difference in the results was elicited.

The venous pulsatility index in the central retinal vein positively correlated with age but this is unlikely to represent an increase in resistance in this vessel (downstream of the measurement site) because the venous outflow into the low pressure cavernous sinus and jugular vein is liable to produce negligible resistance to flow. Instead the index can be used to measure the pulsation in the vein because of its close proximity of the central retinal artery. The relation between the artery and the vein is further illustrated by the positive correlation between the venous pulsatility index from the vein and the resistive index from the artery. It is our opinion that the expansion of the artery with the systemic pulse causes constriction of the vein thereby increasing the velocity. The interpretation of the age related changes on the venous pulsatility requires further study because of the 

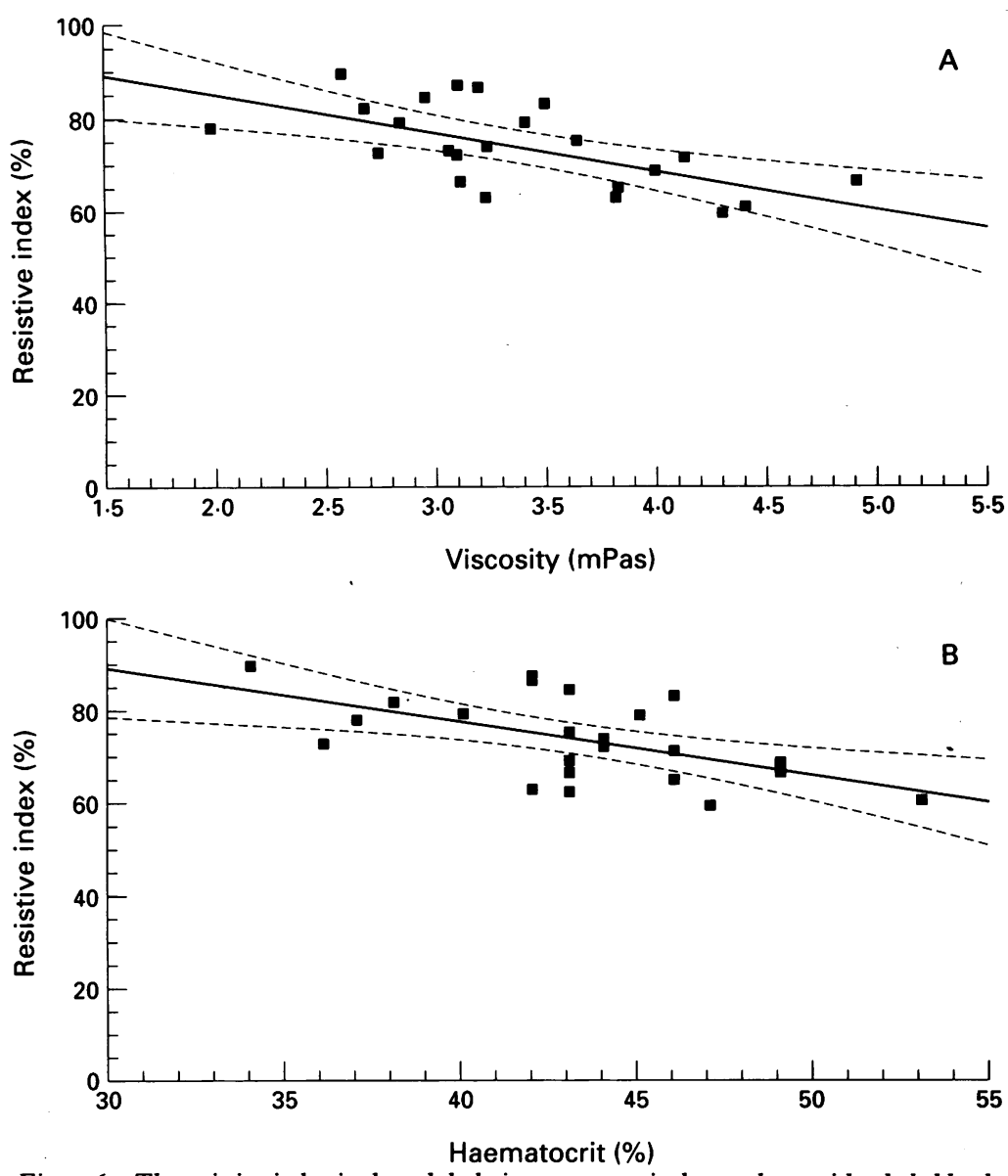

Figure 6 The resistive index in the ophthalmic artery negatively correlates with whole blood viscosity $(A)$ and the haematocrit $(B)$, and may be sign of increased resistance to flow in the carotid circulation (linear regression lines are shown and 95\% confidence intervals).
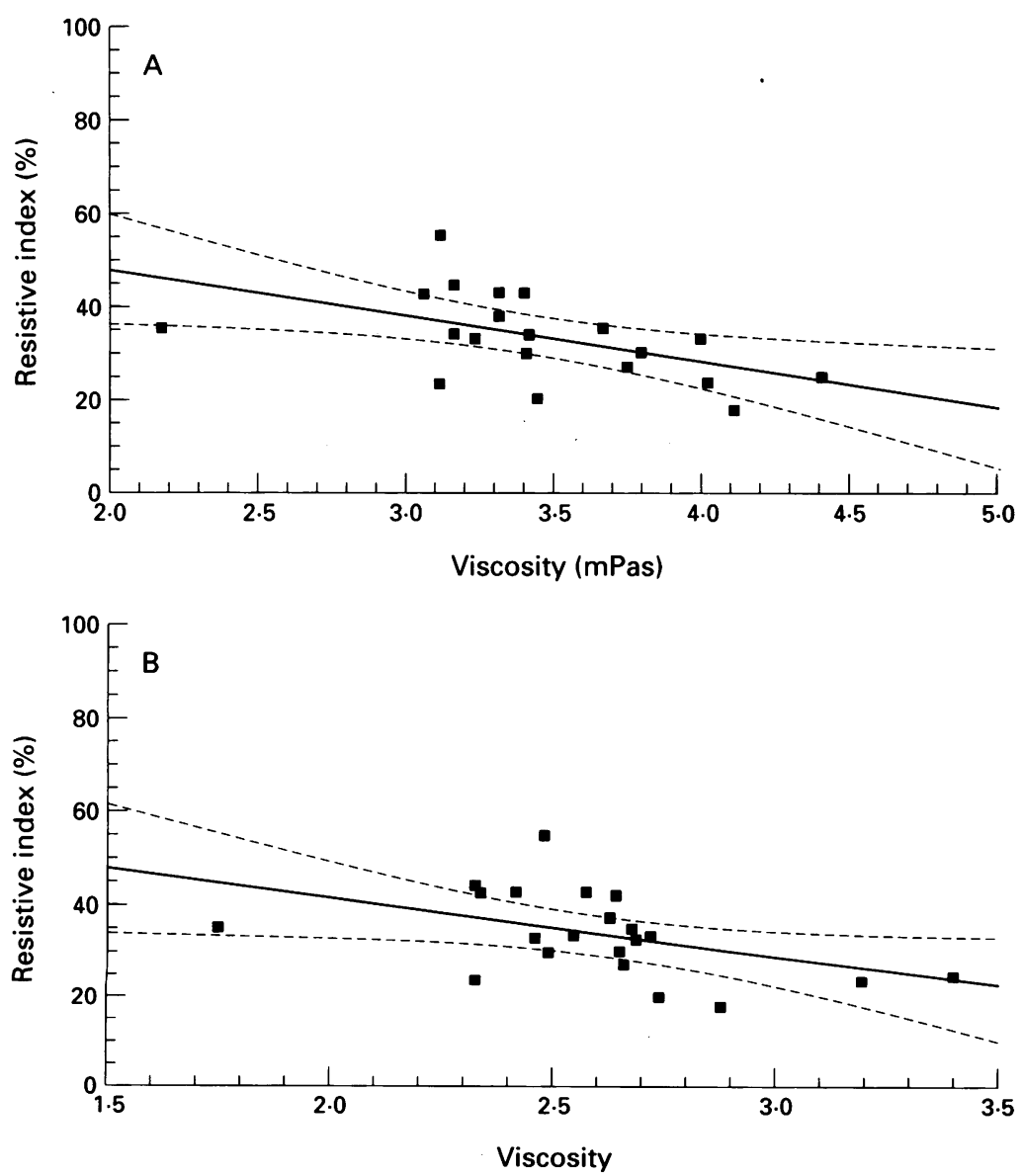

Figure 7 The pulsatility index in the central retinal vein negatively correlates with corrected $(A)$ and relative blood viscosity $(B)$, illustrating that the pulsatility of flow in the vein is reduced probably by increased red cell rigidity (linear regression lines are shown and $95 \%$ confidence intervals). potential effects of narrowing of the vein on the results. ${ }^{22}$

According to the Hagen-Poiseuille law raised blood viscosity tends to reduce blood flow unless compensated by vasodilatation. In this study, the viscosity results did not influence the values for blood velocity in the orbital vessels perhaps because of compensation for the viscosity increase by vasodilatation. In the ophthalmic artery the resistive index was negatively correlated with the haematocrit and whole blood viscosity. Resistive index can be reduced by both increased resistance to flow upstream of the measurement site, and also by decreased resistance to flow downstream. Since haematocrit is the most important determinant of blood viscosity in larger arteries ( $>300 \mu \mathrm{m}$ : the ophthalmic artery has a diameter of approximately $300 \mu \mathrm{m}$ ) but becomes relatively unimportant in smaller arteries and arterioles, these associations may arise from increased resistance to flow in the carotid circulation.

Blood viscosity appears to be an important determinant for the development of stasis or occlusion of the central retinal vein. Diseases with raised blood viscosity such as polycythaemia due to raised haematocrit ${ }^{18}$ and Waldenstrom's macroglobulinaemia due to increased plasma viscosity ${ }^{23}$ often show retinal signs consistent with venous stasis and may develop occlusion of the vein. ${ }^{24}$ Patients with central retinal vein occlusion have been found to have raised viscosity in some studies ${ }^{14152526}$ although not in others. ${ }^{27} 28$ Moreover, blood viscosity increases at low shear rates (found at lower blood velocity and increased blood vessel diameter), and is therefore higher in the venous circulation. In this study, both haematocrit corrected blood viscosity and relative blood viscosity were negatively correlated with the resistive index in the central retinal vein. The results suggests that red cell rigidity reduces the pulsations in the vein. In patients with central retinal vein occlusion the pulsatility in the vein has been found to be reduced in both their affected and contralateral healthy eyes. ${ }^{29}$ The lack of pulsatility of the flow in the vein associated with increased red cell rigidity, may be detrimental to the flow of blood in the central retinal vein and thus increase the risk of stasis or occlusion.

In summary, the blood velocity recordings from the orbital vasculature, in addition to the effects of age, are affected by systemic blood pressure and cigarette smoking. The former should be measured and the latter avoided during studies using colour Doppler imaging. There is also a relation between the pulsatile velocities in these blood vessels and rheological factors. These may be implicated in the pathogenesis of diseases of the eye with which raised blood viscosity has been associated.

1 Erickson SJ, Hendrix LE, Massaro BM, Harris GJ, Lewandowski MF, Foley WD, et al. Color Doppler flow imaging of the normal and abnormal orbit. Radiology 1989 173: $511-6$.

2 Lieb WE, Cohen SM, Merton DA, Shields JA, Mitchell DG Goldberg BB. Color Doppler imaging of the eye and orbit. Technique and normal vascular anatomy. Arch Ophthalmo 1991; 109: 527-31.

3 Baxter GM, Williamson TH, McKillop G, Dutton GN. Color Doppler ultrasound of orbital and optic nerve blood flow: effects of posture and timolol $0.5 \%$. Invest Ophthalmol Vis Sci 1992; 33: 604-10. 
4 Williamson TH, Baxter G, Paul R, Dutton GN. Colour Doppler ultrasound in the management of a case of cranial Doppler ultrasound in the management of

5 Williamson TH, Baxter GM, Dutton GN. Color Doppler velocimetry of the arterial vasculature of the optic nerve head and orbit. Eye 1993; 7: 74-9.

6 Williamson TH, Baxter GM, Dutton GN. Color Doppler velocimetry of the optic nerve head in arterial occlusion. Ophthalmology 1993; 100: 312-7.

7 Lieb WE, Flaharty PM, Sergott RC, Medlock RD, Brown GC, Bosley $T$, et al. Color Doppler imaging provides accurate assessment of orbital blood flow in occlusive carotid artery disease. Ophthalmology 1991; 98: 548-52

8 Ho AC, Lieb WE, Flaharty PM, Sergott RC, Brown GC, Bosley TM, et al. Color Doppler imaging of the ocular Bosley TM, et al. Color Doppler imaging of the oc

9 Baxter GM, Williamson TH. Color Doppler flow imaging in central retinal vein occlusion: a new diagnostic technique? Radiology 1993; 187: 847-50.

10 Guthoff RF, Berger RW, Winkler P, Helmke K, Chumbley LC. Doppler ultrasonography of the ophthalmic and central retinal vessels. Arch Ophthalmol 1991; 109: 532-6.

11 Peduzzi M, Melli M, Fonda S, Codeluppi L, Guerrieri F. Comparative evaluation of blood viscosity in diabetic retinopathy. Int Ophthalmol 1984; 7 : 15-9.

12 Barnes AJ, Locke P, Scudder PR, Dormandy TL, Dormandy $\mathrm{JA}$, Slack J. Is hypoerviscosity a treatable component of diabetic microcirculatory disease? Lancet 1977; ii: 789-91.

13 Isogai Y, Iida A, Michizuki K, Abe M. Hemorheological studies on the pathogenesis of diabetic microangiopathy. Thromb Res 1976; 8: 17-24.

14 Ring CP, Pearson TC, Sanders MD, Wetherley Mein G. Viscosity and retinal vein thrombosis. Brf Ophthalmol 1976; 60: $397-410$.

15 Trope GE, Lowe GD, McArdle BM, Douglas JT, Forbes CD, Prentice CM, et al. Abnormal blood viscosity and haemostasis in long-standing retinal vein occlusion. $\mathrm{Br} \mathcal{F}$ Ophthalmol 1983; 67: 137-42.

16 Pourcelot L. Applications cliniques de l'examinen Doppler transcutane. INSERM 1974; 34: 213-40.

17 Williamson TH, Barr D, Baxter GM. An understanding of the retinal circulation provided by an anomalous retinal vein. Brf Ophthalmol 1994 (in press)

18 Lowe GDO. Blood viscosity in vitro and in vivo. Bailliere's Clin Haematol 1987; 1: 597-637.

19 Grunwald JE, Piltz J, Patel N, Bose S, Riva CE. Effect of ageing on retinal microcirculation: A blue field simulation study. Invest Ophthalmol Vis Sci 1993; 34: 3606-13.

20 Williamson TH, Harris A, Shoemaker JA, Sergott RC, Katz JL, Lieb WE. Reproducibility of color Doppler imaging assessment of blood flow velocity in orbital vessels. Invest Ophthalmol Vis $S$ ci 1994; 35: 1658.

21 Riva CE, Grunwald JE, Sinclair SH, Petrig BL. Blood velocity and volumetric flow rate in human retinal vessels. Invest and volumetric flow rate in human

22 Taylor AW, Sehu W, Williamson TH, Lee W. Morphometric assessment of the central retinal artery and vein in the optic nerve. Can f Ophthalmol 1993; 28: 320-4

23 Rosen ES, Simmons AV, Warnes TW. Retinopathy of Waldenstrom's macroglobulinemia: photographic assessment. Am f Ophthalmol 1968; 65: 696-706.

24 Thomas EL, Olk RJ, Markman M, Braine H, Patz A. Irreversible visual loss in Waldenstrom's macroglobulinaemia. Brf Ophthalmol 1983; 67: 102-6.

25 Piermarocchi S, Segato T, Bertoja H, Midena E, Zucchetto M, Girolami A, et al. Branch retinal vein occlusion: the pathogenetic role of blood viscosity. Ann Ophthalmol 1990; 22: 303-11.

26 Peduzzi M, Debbia A, Guerrieri F, Bolzani R. Abnormal blood rheology in retinal vein occlusion. A preliminary

27 Dodson PM, Galton DJ, Hamilton AM, Blach RK. Retinal vein occlusion and the prevalence of lipoprotein abnormalities. Brf Ophthalmol 1982; 66: 161-4.

28 Wiek J, Schade M, Wiederholt M, Arntz HR, Hansen LL. Haemorheological changes in patients with retinal vein occlusion after isovolaemic haemodilution. Brf Ophthalmol 1990; 74: 665-9.

29 Williamson TH, Baxter GM. Central retinal vein occlusion, an investigation by color Doppler imaging: blood velocity characteristics and prediction of
Ophthalmology 1994; 101: 1362-72. 